\title{
The New Zealand 1986 very low birth weight cohort as young adults: mapping the road ahead
}

Brian A. Darlow ${ }^{1 *}$, L. John Horwood², Lianne J. Woodward ${ }^{3}$, John M. Elliott ${ }^{4}$, Richard W. Troughton ${ }^{4}$, Mark J. Elder $^{5}$, Michael J. Epton ${ }^{6}$, Josh D. Stanton ${ }^{7}$, Maureen P. Swanney ${ }^{7}$, Ross Keenan ${ }^{8}$, Tracy R. Melzer ${ }^{8}$, Victoria A. McKelvey ${ }^{9}$, Karelia Levin ${ }^{1}$, Margaret G. Meeks ${ }^{1}$, Eric A. Espiner ${ }^{10}$, Vicky A Cameron ${ }^{4}$ and Julia Martin ${ }^{1}$

\begin{abstract}
Background: Very low birth weight (less than $1500 \mathrm{~g}$ ) is associated with increased morbidity and costs of health care in childhood. Emerging evidence suggests these infants face a range of health and social problems as young adults. We studied all New Zealand very low birth weight infants born in 1986 (when $58 \%$ were exposed to antenatal corticosteroids) in infancy, with later follow-up at 7 to 8 years and 23 to 24 years. We now aim to assess the cohort at 26-28 years compared with controls.

Methods/design: The case sample will comprise a minimum of 250 members of the 1986 New Zealand national very low birth weight cohort (77\% of survivors). Outcomes will be compared with a control group of 100 young adults born at term in 1986. Following written informed consent, participants will travel to Christchurch for 2 days of assessments undertaken by experienced staff. Medical assessments include growth measures, vision, respiratory function, blood pressure and echocardiogram, renal function, dental examination and blood tests. Cognitive and neuropsychological functioning will be assessed with standard tests, and mental health and social functioning by participant interview. A telephone interview will be conducted with a parent or significant other person nominated by the respondent to gain a further perspective on the young person's health and functioning. All those born at less than 28 weeks' gestation, plus a random subset of the cohort to a total of 150 cases and 50 controls, will be offered cranial magnetic-resonance imaging. Statistical analysis will examine comparison with controls and long-term trajectories for the very low birth weight cohort.
\end{abstract}

Discussion: The research will provide crucial New Zealand data on the young adult outcomes for very low birth weight infants and address gaps in the international literature, particularly regarding cardiovascular, respiratory, visual and neurocognitive outcomes. These data will inform future neonatal care, provide evidence-based guidelines for care of preterm graduates transitioning to adult care, and help shape health education and social policies for this high risk group.

Trial registration: Australian New Zealand Clinical Trials Registry ACTRN12612000995875. Registered 1 October 2012

Keywords: Very low birth weight, Infant, Population based, Follow-up, Psychosocial development, Young adult, Outcomes, Health related quality of life, Cardiovascular, Respiratory function tests

\footnotetext{
*Correspondence: brian.darlow@otago.ac.nz

${ }^{1}$ Cure Kids Professor of Paediatric Research, Department of Paediatrics, University of Otago at Christchurch, PO Box 4345, Christchurch 8140, New Zealand

Full list of author information is available at the end of the article
}

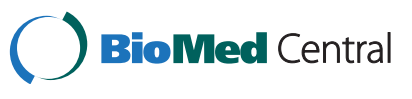

(C) 2015 Darlow et al. This is an Open Access article distributed under the terms of the Creative Commons Attribution License (http://creativecommons.org/licenses/by/4.0), which permits unrestricted use, distribution, and reproduction in any medium, provided the original work is properly credited. The Creative Commons Public Domain Dedication waiver (http:// creativecommons.org/publicdomain/zero/1.0/) applies to the data made available in this article, unless otherwise stated. 


\section{Background}

Infants born very low birth weight (VLBW: $<1500$ g) or very preterm (VP: $<32$ weeks gestation) account for around $2 \%$ of live births but between $50-75 \%$ of the work load of neonatal intensive care units (NICUs) [1]. Whilst survival rates for these infants now exceed $90 \%$, $[2,3]$ what is most important for individuals, their families and society is the quality of that survival in the longer term. Knowledge of longer-term outcomes is also crucial to inform current neonatal care.

An extensive literature has documented increased rates of health problems amongst surviving VLBW/VP infants compared with full term infants in their early years, including sudden infant death syndrome, feeding problems, respiratory disorders, and increased hospitalisation [4]. Adverse outcomes are also common throughout childhood and include poor growth, neurosensory impairments such as cerebral palsy (CP) in up to $10 \%$ or more, and up to $50 \%$ have behavioural problems, cognitive delay, or educational underachievement [5-11]. Woodward [12] reported that $72 \%$ of VP infants have some white matter (WM) changes on cranial MRI scans at term equivalent, and that moderate or severe changes (in $21 \%$ ) were predictive of $\mathrm{CP}$ and neuro-cognitive problems in early childhood. These abnormalities include reduced WM volume, ventriculomegaly, thinning of the corpus callosum and delayed myelination. The impacts of these neonatal neurological abnormalities on adult brain structure and function are not known. However, findings from cross sectional studies in childhood and adolescence, [13-15] and a recent cohort study, [16] suggest that abnormalities persist and may be irreversible.

Data are also now emerging on a range of functional and health related challenges faced by former VLBW/VP infants as they reach young adulthood, $[17,18]$ although the majority appear to do well overall [19-21]. Scandinavian data show that preterm birth and particularly lower gestational age is associated with increased mortality in young adulthood, $[22,23]$ with congenital abnormalities, respiratory, endocrine and cardiovascular problems all increasing hazard ratios for risk of death [23]. Studies of growth of VLBW/VP children show that following early growth failure there is some catch-up that may continue through adolescence, although young adults remain shorter and often lighter than their peers [24]. Specific health issues found to be more prevalent include an increased risk of hypertension, $[18,25,26]$ impaired insulin sensitivity, [27] glucose tolerance, [28] and renal function $[29,30]$ and abnormal respiratory function [25, 31]. VLBW children have a greater risk of asthma at school age than controls [32] and infants who had chronic lung disease have poorer lung function in late adolescence [25]. In addition, most reports to date indicate that former VLBW/VP young adults do have lower median IQ scores than their peers, even after excluding those with neurosensory impairments and controlling for confounding factors. Relatively fewer VLBW/VP survivors graduate from high school or enter tertiary education $[17,18,33]$. And even when free of major physical disability, VP young adults performed less well on tasks involving mental flexibility and response inhibition [34].

There are no New Zealand data in this crucial area and important gaps exist in the international literature. To address both these issues we will follow-up the 1986 New Zealand national cohort of VLBW infants, at age 26-28 years.

In 1986 we enrolled all 413 New Zealand VLBW infants admitted to a neonatal intensive care unit (NICU) as part of a prospective study of acute retinopathy of prematurity. Of these, 338 infants (82\%) survived to discharge home [35, 36]. Extensive perinatal data collection showed that at birth $58 \%$ had received antenatal steroids, $132(32 \%)$ were $<1000 \mathrm{~g}, 126$ (31 \%) were $<28$ weeks gestation, 103 (25\%) were small for gestational age, and 95 (23\%) were Maori. Survival for both those $<1000 \mathrm{~g}$ and $<28$ weeks was $64 \%[2,36]$.

This cohort was followed-up at 7 to 8 years and assessments conducted to examine visual and developmental outcomes. By this age a further 12 children had died, 17 were traced to an overseas address, seven families declined follow-up and four were untraced. Hence we assessed 298 children (96\% survivors resident in NZ, $91 \%$ all survivors): $5 \%$ had severe disability, $5 \%$ moderate disability and $15 \%$ mild disability, which was principally an IQ between 1 to 2 SDs below the mean [9]. Compared with the Christchurch Health and Development Study cohort studied at the same age, [37] the VLBW cohort had higher rates of behavioural problems (conduct disorders, attention problems, anxiety/withdrawal), and poorer school achievement [10]. These differences increased with decreasing birthweight amongst the VLBW sample.

In 2009-10, when the members of the cohort were 23 to 24 years old, they were re-contacted as part of a feasibility study in preparation for funding applications for the current project. VLBW graduates were traced through their addresses at 7 to 8 years, grandparents' addresses, general practitioners, National Health Index (NHI) codes (NHI - a unique person identifier used within the New Zealand health system since 1993), via the electoral rolls and, in a limited number of cases, by local advertisements. Checks were made with Statistics New Zealand to see if any individuals had died since last follow-up. A comparison group (controls) of individuals who were born full-term (FT) in New Zealand in 1986 and were not admitted for NICU care, was recruited either through peer nomination by cohort members or via 
random sampling from electoral rolls, ensuring balance with respect to the gender, ethnicity and regional distribution of the sample.

A total of 276 ( $85 \%$ of 324$)$ survivors were retraced and 230 (71 \%) enrolled in this pilot (Phase 1) study, which comprised a face-to-face interview to collect information about each participant's social background, health, education and social role outcomes, supplemented by information from medical records [38]. Sixty-nine controls were also recruited.

The present (Phase 2) study has two primary aims.

The first aim is to assess the health, mental status, functional outcome and quality of life in young adulthood of a NZ national VLBW cohort born in 1986 compared with a group of full-term children born in the same year.

We hypothesise that compared to their same age full term peers, adults born VLBW will, at age $26-28$ years, have:

1. Lower levels of school attainment and tertiary educational participation, more limited occupational choice and higher levels of welfare dependence

2. Higher levels of inattention, impulsivity and emotional problems (i.e., symptoms of anxiety and depression), but lower levels of alcohol and drug use/abuse, antisocial behaviour and police contact.

3. Lower social participation and poorer social functioning

4. Poorer performance on measures of cognitive ability, information processing and executive functioning

5. Increased rates of cardiovascular, endocrine, pulmonary, renal and visual abnormalities and pathology

Specifically, regarding cardiovascular assessments, we anticipate:

- Lower reactive hyperaemia consistent with more endothelial dysfunction

- Echocardiograms that show more abnormalities in LV size and function

- Elevation of BNP and other cardiac biomarkers and related signalling peptides, that reflect the degree of cardiovascular abnormality and will predict future cardiovascular events regarding endocrine assessments, we anticipate:

- Higher indices of insulin resistance and glucose intolerance

regarding pulmonary function, we anticipate:

- Impaired pulmonary function, including reduced lung volumes and diffusing capacity, reduced exercise capacity, and higher rates of respiratory morbidity.

regarding renal function, we anticipate:

- Higher microalbumin excretion and lower creatinine clearance regarding vision, we anticipate:

- Less favourable structural outcomes and impaired functional ability

6. Poorer dental health and dental hygiene

7. Increased rates of both macro- and micro-structural abnormalities on cranial MRI scans

The second aim is to assess whether childhood health and developmental outcomes are predictive of later young adult outcomes within the VLBW cohort.

We hypothesise that within the VLBW cohort:

8. Young adults who were characterised by significant disability/cognitive impairment at 7 to 8 years will fare less well on measures 1-4 than VLBW adults without early impairment [39].

9. Young adults who had retinopathy of prematurity (ROP) and visual impairments at 7 to 8 years will have more adverse visual problems than those who had no ROP.

10. Young adults who had neonatal chronic lung disease (CLD) will have more adverse respiratory function than those who no CLD

11. Increased duration of breastfeeding will be associated with a small but measurable advantage in cognitive outcomes

12. There will be increasing social and economic disadvantage with decreasing birthweight and increasing prematurity.

In our preliminary (Phase 1) study we re-established the cohort and began to address hypotheses 1-3. This Phase 2 study will extend the research to focus on health issues and neurocognitive outcomes but also to update the information collected as part of Phase 1.

\section{Design and methods Study population}

The case sample will comprise a minimum of 250 members of the 1986 NZ National VLBW cohort (77 \% of survivors). In Phase 1 the proportion (\%) of the 230 survivors seen and other survivors not assessed (94) who were $<1000 \mathrm{~g}$ was 25.2 and 27.1; were $<28$ weeks is 24.8 and 24.0; are male is 47.0 and 52.1; are Maori is 26.1 and 22.1; had moderate/ severe disability at 7 to 8 years is 10.3 and 6.7 - all being not significantly different. Outcomes for the VLBW cohort will be assessed against a comparison sample of 100 same age term controls recruited via a process of peer nomination and random sampling from electoral rolls, ensuring balance with respect to the gender, ethnicity and regional distribution of the sample. 


\section{Procedures}

As part of Phase 1 all participants have been informed about Phase 2 of the study and have consented to being approached to participate in these assessments. The study has also obtained comprehensive contact information for each participant, plus a number of individuals not studied in Phase I, and we do not anticipate major difficulties in tracing and consenting participants for Phase 2. Following consent, participants will be brought to Christchurch for a 2 day multidisciplinary evaluation (an average of three participants a week). Provision will be made for a support person to travel with the participant if this is required. All costs of travel, accommodation and food will be met by the study. For the small number of the cohort members who are too compromised to travel to Christchurch due to disability severity and/or care needs we will seek information by means of a questionnaire and, where possible, a visit from one of the research team (Additional files 1, 2, 3, 4, 5, 6).

All research procedures will be conducted in existing facilities in the University of Otago, Christchurch or Canterbury District Health Board (CDHB). Participants will be scheduled to arrive the night before, have fasting blood tests the next morning and a series of assessments over 2 days. Study personnel will meet each participant and assist their navigation between laboratory sessions. To avoid problems of fatigue, participants will have the opportunity to take breaks as necessary and refreshments as required. Transportation will also be provided when needed.

Medical investigations will be undertaken in the University of Otago, Christchurch, Department of Medicine Nicholls Clinical Research Centre and the CDHB Respiratory Physiology Laboratory facilities.

Assessments will be conducted by appropriately trained, medically qualified staff, who will be blinded to the participant's background (except where noted otherwise), and will include:

- Standardised questionnaires on health, including respiratory [40] and bowel problems.

- Growth-height (Harpenden stadiometer), weight, BMI (Weight/Height ${ }^{2}$ ), waist-hip ratio, head circumference.

- Total body fat estimated by bioelectrical impedance analysis (BIA).

- Visual assessment. Glasses prescription-measured in focimeter. Distance visual acuity using standardised ETDRS chart (with glasses if worn). Contrast sensitivity testing with Pelli-Robson charts (which reflects functional visual ability). Autorefraction. Retinal photographs to digitally record macula, optic disk, paracentral and peripheral retina.
- Blood pressure assessed using a random zero machine (seated, after rest for 5 min, cuff size 2/3 upper arm length: mean of three readings)

- Echocardiogram for left ventricular volume, mass and function, valves, ascending aorta dilatation. Measurement of myocardial velocities and deformation.

- Endothelial dysfunction assessment by peripheral arterial tonometry (EndoPAT), [41] consisting of digital recording equipment and two finger thimble-like probes.

- Respiratory Function Tests. Forced expiratory volume in $1 \mathrm{~s}\left(\mathrm{FEV}_{1}\right)$, Forced Vital Capacity (FVC) and $\mathrm{FEV}_{1} /$ FVC [42]. Static lung volumes [43]. Diffusing capacity of CO [44]. Single breath nitrogen washout [45].

Maximal exercise testing [46].

- Renal function, assessed by a) creatinine clearance $\left(\mathrm{C}_{\mathrm{cl}}\right)$ - [Blood test for plasma creatinine in $\mathrm{mmol} / \mathrm{L} . \mathrm{C}_{\mathrm{cl}}$ calculated from Cockcroft-Gault approximation] and $b$ ) early morning urine for albumin-creatinine ratio [mg/ mmol: $<2.2$ normal; 2.2-22.6 microalbuminuria; $>22.6$ proteinuria].

- Additional venous blood sample for:

Fasting insulin and glucose - (insulin sensitivity calculated from QUICKI [47]) lipids; glycated haemoglobin; cotinine.

Plasma hormones including B-Type Natriuretic Peptide (BNP), amino terminal proBNP (NT-proBNP), C-Type Natriuretic Peptide (CNP), amino terminal proCNP (NTproCNP), high sensitivity troponin $\mathrm{T}$ (hsTNT), renin, aldosterone.

Stored plasma sample for future use - investigation of gene-environment interactions; biochemical assays.

Blood volume: $5 \times 9 \mathrm{ml}$ EDTA, plus $3 \mathrm{ml} \mathrm{A} 2$, plus $2 \times$ $9 \mathrm{ml}$ lithium heparin for hormones and storage. Plus $4 \mathrm{ml}$ lithium heparin for biochemistry. Total $70 \mathrm{ml}$.

Total time for tests including breaks is estimated at about 2.5-3.5 h (medical/cardiology 1-1.5 h, respiratory tests $1-1.5 \mathrm{~h}$, visual assessments $0.5 \mathrm{~h}$ ).

Oral Health investigations will be undertaken by dentists from the oral health service of the Canterbury District Health Board using a standardised protocol from the 2009 New Zealand Oral Health Survey [48]. The examination will include assessments of the wearing of dentures; history of orthodontic treatment; the health of oral mucosa; tooth loss, presence of decay, and dental treatments; plaque, calculus, gingivitis; periodontal tissue destruction; decay experience of coronal and root surfaces; and the presence of enamel defects. Total examination time will be approximately $45 \mathrm{~min}$. Dental examination will be supplemented by questionnaire data on current problems or concerns about oral health, practise of dental hygiene and use of dental health services. 
Neuropsychological Functioning will be assessed in other existing facilities in the University of Otago, Christchurch, by research staff with appropriate training and qualifications in psychometric test administration. The test room will be suitably quiet. The tester will be blinded to the participants' background. Testing will take between 2 to $3 \mathrm{~h}$ for each participant, including breaks as needed, and will include assessments of:

- Global cognitive ability/IQ will be assessed using the Wechsler Abbreviated Scale of Intelligence ${ }^{\bullet}$ Second edition (WASI-II), [49] an individually administered assessment of intelligence for people aged 6-90 years. This short form consists of four subtests including Block Design and Matrix Reasoning (which compose the Perceptual Reasoning Index) and the Vocabulary and Similarities subtests (which compose the Verbal Comprehension Index).

- Attention will be measured using the Test of Everyday Attention (TEA), [50] which assesses selective attention, sustained attention and switching attention.

- Working memory - Visual working memory will be assessed using a computer administered task adapted from the Sternberg Spatial Working Memory Paradigm [51]. Auditory working memory will be assessed using the two elevator counting tasks of the Test of Everyday Attention: Elevator counting with distraction; Elevator counting with reversal.

- Cognitive flexibility will be assessed by the Comprehensive Trail Making Test (CTMT), [52] comprising a standardized set of five visual search and sequencing tasks, and the Brixton Spatial Anticipation Test, [53] which is a measure for assessing the ability to detect and follow a rule.

- Visuo-spatial processing and planning will be assessed using the Benton Judgement of Line Orientation Form $V$ [54].

- Information processing speed will be assessed using the Symbol Digit Modalities Test [55].

For participants with a physical or sensorineural disability some tests may not be possible, and where possible an alternative form of the test will be used.

Health and social functioning Trained survey interviewers will update information from study Phase 1 on education, occupational status, health history and selfassessment of health status, quality of life measures, current mental health, substance use, family, peer and partner relationships and other aspects of social functioning. Interviews ( 2 to $3 \mathrm{~h}$ ) will be conducted in private.
Parent/significant other report To gain a further perspective on the young person's health and functioning, a telephone interview will be conducted with a parent or significant other person nominated by the respondent. These interviews will gather a third person perspective on aspects of the young person's health and health history, education and transition to adult roles, the young person's behaviour and personality, social and partner relationships and related issues. Interviews will take 35-45 min and will be conducted by trained survey interviewers who are independent of the survey team interviewing the young person, but are not blinded their background.

Magnetic resonance imaging We will undertake a cranial MRI scan on all participants who were born at $<28$ weeks gestation and a random sample of the VLBW cohort to bring the total having MRI scans to 150 , plus a random 50 controls. Images will be acquired using a 3-Tesla GE scanner on the Christchurch campus and analyses undertaken by experienced staff blinded to the participants' background. Scanning will take a total of 35-45 min comprising:

- Clinical data - T2 and T2 FLAIR images as part of standard clinical protocol for purposes of a radiologist $\mathrm{read} / \mathrm{referral} / \mathrm{exclusion}$ and qualitative scoring

- T1-weighted images will be used to assess brain growth and tissue distribution

- Diffusion Tensor imaging (DTI) will assess white matter microstructural development (fractional anisotropy).

- Arterial Spin Labelling (ASL) - a non-invasive functional measure of cerebral blood flow that produces quantification of cerebral perfusion and has good concordance with ${ }^{15} \mathrm{O}$-PET [56]

- Resting State Functional Connectivity (fcMRI) which provides a method to evaluate regional interactions in the brain.

Both ASL and fcMRI may be clinically useful as biomarkers for individuals at increased risk of later cognitive impairment. This protocol, with the addition of ASL, is the same as that being used at 12 years of age in a cohort of former $<32$ week gestation children, who also had MRI scans at term equivalent, [12] and this may allow early clues as to longitudinal trajectories of brain injury and neural plasticity.

\section{Additional studies}

Although not part of the primary protocol for the New Zealand 1986 VLBW Follow-up Study, we will also undertake two additional studies with separate funding. 
1. DNA methylation and outcomes in VLBW young adults. We will investigate whether young adults born with VLBW have differences in DNA methylation at specific sites in the genome (in peripheral blood samples), compared with a matched normal birthweight group, and whether these traits are associated with growth and metabolic health outcomes as young adults. Separate consent is required for this study, which also requires an additional $10 \mathrm{ml}$ blood sample be taken.

2. $C$ type Natriuretic Peptide (CNP) and vascular risk in VLBW young adults. CNP is a paracrine vasoprotective peptide secreted by the vascular endothelium, and which has anti-inflammatory actions in rodents and has been shown to be atheroprotective. Very little CNP normally enters the circulation but a stable product of the prohormone (amino terminal proCNP, NTproCNP) can be readily measured in plasma and serves as a marker of CNP production in tissues. Recent studies by the Christchurch group have defined the normal age and gender related ranges of plasma NTproCNP concentration in 250 healthy adult subjects without known history of cardiovascular disorder [57]. We will compare the plasma NTproCNP concentrations in VLBW young adults and term born controls and investigate their relationship with individual vascular risk factors and with adult height.

\section{Statistical analysis and statistical power}

The collected data will enable two types of analyses to be conducted. Between group comparisons: The principal analyses will examine between group differences in outcome (health, neurocognitive assessments, social functioning), using standard statistical analyses: chi square for differences in proportions; $t$-test for independent samples or analysis of variance for differences in means of continuous outcomes; Poisson or negative binomial regression for differences in rates. Where outcome data are non-normally distributed appropriate data transformations (eg logarithmic) may be conducted. The VLBW group may be further subdivided to test for differential effects by severity of disability at age 7 to 8 , or by birthweight or gestation. Comparisons may be further adjusted if necessary for between group differences in family background characteristics using regression methods based on the generalised linear model [58]. Assuming a minimum of 250 recruits from the VLBW cohort and 100 controls, the study will have $80 \%$ power at alpha $=.05$ to detect differences between groups of $30 \mathrm{SD}$ or greater on continuous outcomes, and ORs in the region of 2.0-3.5 for dichotomous outcomes (depending on the base rate) [59]. This suggests the study will have adequate power to detect effect sizes in the small to moderate range. These differences are well within the anticipated effect sizes based on existing reports $[17,18]$. Subdividing the VLBW group (for example by level of prior disability) is unlikely to compromise study power since the effect sizes are likely to increase for more extreme groups.

Outcome trajectories amongst the VLBW cohort: For a number of outcomes, for example visual, physical growth, it will be possible to examine across time continuities and/or trajectories in outcome from childhood to adulthood within the VLBW cohort. Depending on the outcome under consideration, analysis methods may range from simple tabular methods documenting outcome in young adulthood conditional on childhood status, to simple regression models predicting outcome in adulthood from measures in childhood, to more complex methods for repeated measures data based on a generalised estimating equation approach [60] to model changes in outcome trajectory.

\section{Ethics}

The study has received ethics approval from the Upper South B Regional Ethics Committee (superseded by the Southern Health and Disability Committee) (ref: URB/12/05/015).

\section{Discussion}

The study of adult outcomes after VLBW/VP birth is a relatively new field and one which is expanding, but there are important gaps in current knowledge. Many cohorts date from the 1970's or early 1980's when few infants received antenatal steroids, which reduce both mortality and morbidity [61]. Some studies are from single institutions, [17,62] or a group of institutions, including the Helsinki Study of Very Low Birth Weight Adults based on 166 VLBW infants born in 1978-85 and which has been highly productive $[26,63]$. Of the few population based studies most are regional $[17,18]$ or rely on constrained national registry data [19] (Swedish, [64, 65] Norwegian [66] and Danish [67] studies). The Netherlands study of VP/VLBW infants born in $1983[68,69]$ is most similar to our NZ cohort but these infants were not exposed to antenatal corticosteroids. As more data become available, understanding trends across studies as well as differences between them will become important. The New Zealand 1986 VLBW Follow-up Study investigators are committed to collaborating with other studies as part of the Adult Born Preterm International Collaboration (APIC), which has been initiated by the Helsinki, Finland group [70].

\section{Additional files}

Additional file 1: NZ 1986 VLBW FU Study Cohort Information Sheet May 2013 Final. 


\section{Additional file 2: NZ 1986 VLBW FU Study Controls Information Sheet May 2013 Final.}

Additional file 3: NZ 1986 VLBW FU Study Information Sheet Genetics August 2012.

\section{Additional file 4: NZ 1986 VLBW FU Study Consent Form Genetics} Jan 2013.

Additional file 5: NZ 1986 VLBW FU Study Consent Form Genetics Jan 2013.

Additional file 6: NZ 1986 VLBW FU Study Explanation of procedures June 2013.

\section{Abbreviations}

VLBW: Very low birth weight; VP: Very preterm; NICU: Neonatal intensive care unit; CP: Cerebral palsy; WM: White matter; MRI: Magnetic resonance imaging; IQ: Intelligence quotient; SD: Standard deviation; NHI: National Health Index; FT: Full-term; NZ: New Zealand; ROP: Retinopathy of prematurity; CLD: Chronic lung disease; CDHB: Canterbury District Health Board; BMI: Body-mass index; BIA: Bioelectrical impedance analysis; ETDRS: Early treatment diabetic retinal study; EndoPAT: Peripheral arterial tonometry; FEV ${ }_{1}$ : Forced expiratory volume in $1 \mathrm{~s}$; FVC: Forced vital capacity; CO: Carbon monoxide; $C_{\mathrm{c}}$ : Creatinine clearance; QUICKI: Quantitative insulin sensitivity check index; BNP: B-Type natriuretic peptide; CNP: C-Type natriuretic peptide; hsTNT: High sensitivity troponin T (hsTNT); EDTA: Ethylenediaminetetraacetic acid; WASI: Wechsler Abbreviated Scale of Intelligence ${ }^{\oplus ;}$ TEA: Test of everyday attention; CTMT: Comprehensive trail making test; DTI: Diffusion tensor imaging; ASL: Arterial spin labelling (ASL); fc: Functional connectivity; APIC: Adult born preterm international collaboration.

\section{Competing interests}

All authors declare that they have no competing interests.

\section{Authors' contributions}

BAD conceived the study concept, led the protocol design and wrote the first draft of the manuscript. LJH contributed to the study concept and protocol design and is responsible for the statistical analysis plan. LJW, JME and RWT contributed to the study concept and protocol design. All remaining authors (MJE, ME, JS, MS, RK, TRM, VMCK, KL, MM, EAE, VC, JM) contributed to the protocol design. All authors read, revised and approved the final version of the manuscript.

\section{Acknowledgements}

The Study is funded by the New Zealand Health Research Council (12/129) through a competitive project grant with some co-funding from the Cure Kids charity. Additional funding is from two project grants from the Child Health Research Foundation (Cure Kids) (CHRF 5040, 5041). The Canterbury Neonatal Unit Trust Fund has generously funded the cost of the EndoPAT machine and, as consumer stakeholders with an interest in the outcomes of this research, wrote a supportive letter at the time of grant applications. A replacement autorefractor was purchased through University of Otago capital funds. Finally, we are very grateful to all the young adult participants for their willingness to take part in this study.

\section{Author details}

${ }^{1}$ Cure Kids Professor of Paediatric Research, Department of Paediatrics, University of Otago at Christchurch, PO Box 4345, Christchurch 8140, New Zealand. ${ }^{2}$ Christchurch Health and Development Study, Department of Psychological Medicine, University of Otago at Christchurch, PO Box 4345, Christchurch 8140, New Zealand. ${ }^{3}$ Director of Infant and Child Development Research, Department of Pediatric Newborn Medicine. Brigham \& Women's Hospital, Harvard Medical School, Boston, MA 02115, USA. ${ }^{4}$ Christchurch Heart Institute, University of Otago at Christchurch, PO Box 4345, Christchurch 8140, New Zealand. ${ }^{5}$ Department of Surgery, University of Otago at Christchurch, PO Box 4345, Christchurch 8140, New Zealand. ${ }^{6}$ Canterbury Respiratory Research Group, 40 Stewart Street, Christchurch, New Zealand. ${ }^{7}$ Respiratory Services, Christchurch Hospital, Private Bag 4710, Christchurch, New Zealand. ${ }^{8}$ New Zealand Brain Research Institute, University of Otago at Christchurch, PO Box 4345, Christchurch 8140, New Zealand. ${ }^{9}$ Oral Health Services, Christchurch Hospital, Private Bag 4710, Christchurch, New Zealand. ${ }^{10}$ Department of Medicine, University of Otago at Christchurch, PO Box 4345, Christchurch 8140, New Zealand.
Received: 18 February 2015 Accepted: 29 July 2015

Published online: 05 August 2015

\section{References}

1. Darlow BA, Mogridge N, Horwood $\amalg$, et al. Admission of all gestations to a regional neonatal unit versus controls: Neonatal morbidity. J Paediatr Child Health. 2009;45:181-6.

2. Darlow BA, Cust AE, Donoghue DA. Improved outcomes for very low birthweight infants: evidence from New Zealand national population based data. Arch Dis Child. 2003;88:23-8

3. Chow SSW. Report of the Australian and New Zealand Neonatal Network 2011. Sydney: ANZNN; 2013.

4. Wilson-Costello D. Is there evidence that long-term outcomes have improved with intensive care? Semin Fetal Neonatal Med. 2007;12:344-54.

5. Allen MC. Preterm outcomes research: a critical component of neonatal intensive care. MRDD Res Reviews. 2002;8:221-33.

6. Marlow N. Neurocognitive outcome after very preterm birth. Arch Dis Child. 2004;89:F224-8

7. Aarnoudse-Moens GSA, Weisglas-Kuperus N, van Goudoever JB, Oosterlaan J. Meta-analysis of neurobehavioural outcomes in very preterm and/or very low birth weight children. Pediatrics. 2009;124:717-28.

8. Doyle LW. Evaluation of neonatal intensive care for extremely low birth weight infants in Victoria over two decades: 1. Effectiveness. Pediatrics. 2004;113:505-9.

9. Darlow BA, Horwood LJ, Mogridge N, Clemett RS. Prospective study of New Zealand very low birthweight infants: Outcome at 7 to 8 years. J Paediatr Child Health. 1997:33:47-51.

10. Horwood LJ, Mogridge N, Darlow BA. Cognitive, educational, and behavioural outcomes at 7 to 8 years in a national very low birthweight cohort. Arch Dis Child Fetal Neonatal Ed. 1998;78:F12-20.

11. Woodward LJ, Moor S, Hood KM, et al. Very preterm children show impairments across multiple neurodevelopmental domains by age 4 years. Arch Dis Child Fetal Neonatal Ed. 2009:94:F339-44.

12. Woodward LJ, Anderson PJ, Austin NC, et al. Neonatal MRI to predict neurodevelopmental outcomes in preterm infants. N Engl J Med. 2006;355:685-94

13. Allin M, Nosarti C, Narberhaus A, et al. Growth of the corpus callosum in adolescent born preterm. Arch Pediatr Adolesc Med. 2007:161:1183-9.

14. Constable RT, Ment LR, Vohr BR, et al. Prematurely born children demonstrate white matter microstructural differences at 12 years of age, relative to term control subjects: an investigation of group and gender effects. Pediatrics. 2008;121:306-16.

15. Eikenes L, Lohaugen GC, Brubakk A-M, et al. Young adults born preterm with very low birth weight demonstrate widespread white matter alterations on brain DTI. Neuroimage. 2011;54:1774-85.

16. Allin MP, Kontis D, Walshe M, et al. White matter and cognition in adults who were born preterm. PLoS One. 2011;6(10):e24525.

17. Hack M. Adult outcomes of preterm children. J Dev Behav Pediatr 2009;30:460-70.

18. Doyle LW, Anderson PJ. Adult outcomes of extremely preterm infants. Pediatrics. 2010:126:342-51.

19. Saigal SJ, Streiner D. Socio-economic achievements of individuals born very preterm at the age of 27 to 29 years. Dev Med Child Neurol. 2009:51:845-50.

20. Zwicker JG, Harris SR. Quality of life of formerly preterm and very low birth weight infants from preschool age to adulthood: a systematic review. Pediatrics. 2008:121:e366-76.

21. Gäddlin P-O, Finnström O, Sydsjö G, Leijon I. Most very low birth weight subjects do well as adults. Acta Paediatr. 2009;98:1513-20.

22. Swamy GK, Ostbye T, Skjaerven R. Association of preterm birth with long-term survival, reproduction, and next-generation preterm birth. JAMA 2008;299:1429-36.

23. Crump C, Sundquist K, Sundquist J, Winkleby MA. Gestational age at birth and mortality in young adulthood. JAMA. 2011;306:1233-40.

24. Euser AM, de Wit CC, Finken MJ, Rijken M, Wit JM. Growth of preterm born children. Hom Res. 2008;70:319-28.

25. Doyle LW. Cardiopulmonary outcomes of extreme prematurity. Semin Perinatol. 2008;32:28-34

26. Hovi P, Andersson S, Räikkönen $K$, et al. Ambulatory Blood Pressure in Young Adults with Very Low Birth Weight. J Pediatr. 2010;156:54-9. e1. 
27. Hofman P, Regan F, Jackson WE, et al. Premature birth and later insulin resistance. N Engl J Med. 2004;351:2179-86.

28. Hovi P, Andersson S, Eriksson JG, et al. Glucose regulation in young adults with very low birth weight. N Engl J Med. 2007;356:2053-63.

29. Kreijzer-Veen MG, Schrevel M, Finken MJ, et al. Microalbuminuria and lower glomerular filtration rate at young adult age in subjects born very premature and after intrauterine growth retardation. J Am Soc Nephrol. 2005;16:2762-278.

30. Rodriguez-Soriano J, Aguirre M, Oliveras R, Vallo A. Long-term renal follow-up of extremely low birth weight infants. Pediatr Nephrol. 2005;20:579-84.

31. Evensen KAl, Steinshamm S, Tjønna AE, et al. Effects of preterm birth and fetal growth retardation on cardiovascular risk factors in young adulthood. Early Human Devel. 2009;85:239-45.

32. Darlow BA, Horwood LJ, Mogridge N. Very low birthweight and asthma by age seven years in a national cohort. Pediatr Pulmonol. 2000;30:291-6.

33. Aylward GP. Neurodevelopmental outcomes of infants born prematurely. J Dev Behav Pediatr. 2005;26:427-40.

34. Nosarti C, Giouroukou E, Micali N, Rifkin L, Morris RG, Murray RM. Impaired executive functioning in young adults born very preterm. J Int Neuropsychol Soc. 2007;18:1-11.

35. Darlow BA. Incidence of retinopathy of prematurity in New Zealand. Arch Dis Child. 1988;63:1083-6.

36. Darlow BA, Horwood LJ, Clemett RS. Retinopathy of prematurity: Risk factors in a prospective population based study. Paediatr Perinat Epidemiol. 1992;6:62-80.

37. Christchurch health and Development Study (webpages). URL http://www.otago.ac.nz/christchurch/research/healthdevelopment/ index.htm Accessed January 2015

38. Darlow BA, Horwood $\sqcup$, Pere-Bracken H, Woodward L. Psychosocial outcomes of young adults born very low birth weight. Pediatrics. 2013;132:e1521-8.

39. Fergusson DM, Horwood LJ, Ridder EM. Show me the child at seven II: Childhood intelligence and later outcomes in adolescence and young adulthood. J Child Psych Psychiatry. 2005;46:850-8.

40. Burney PG, Luczynska C, Chinn S, Jarvis D. The European Community Respiratory Health Survey - study protocol. Eur Respir J. 1994;7:954-60.

41. Rubinshtein R, Kuvin JT, Soffler M, et al. Assessment of endothelial function by non-invasive peripheral arterial tonometry predicts late cardiovascular adverse events. Eur Heart J. 2010;31:1142-8.

42. Miller MR, Hankinson J, Brusasco V, et al. Standardisation of spirometry. Eur Respir J. 2005;26:319-38.

43. Wanger J, Clausen $J$, Coates A, et al. Standardisation of the measurement of lung volumes. Eur Respir J. 2005;26:511-22.

44. Maclntyre N, Crapo RO, Viegi G, et al. Standardisation of the single breath determination of carbon monoxide uptake in the lung. Eur Respir J. 2005;26:720-35.

45. Ruppel G. Manual of pulmonary function testing. St Louis, Mo: Mosby Elsevier; 2009.

46. American Thoracic Society, American College of Chest Physicians. ATS/ACCP Statement on cardiopulmonary exercise testing. Am J Respir Crit Care Med. 2003;167:211-77.

47. Muniyappa R, Lee S, Chen H, Quon MJ. Current approaches for assessing insulin sensitivity and resistance in vivo: advantages, limitations, and appropriate use. Am J Physiol Endocrinol Metab. 2008;294:E15-26.

48. Ministry of Health. Methodology Report for the 2009 New Zealand Oral Health Survey. Wellington: Ministry of Health; 2010.

49. Wechsler D. Wechsler Abbreviated Scale of Intelligence-Second Edition Manual. Bloomington, MN: Pearson; 2011.

50. Robertson $\mathbf{H}$, Ward T, Ridgeway V, Nimmo-Smith I. The structure of normal human attention: The Test of Everyday Attention. J Int Neuropsychol Soc. 1996;2:525-34

51. Sternberg S. High-speed scanning in human memory. Science. 1966;153:652-4

52. Reynolds CR. Comprehensive Trail Making Test. Austin, TX: Pro-Ed; 2002. doi:10.1177/0734282905282415

53. Burgess P, Shallice T. The Hayling and Brixton Tests. Test manual. Bury St Edmunds, UK: Thames Valley Test Company; 1997.

54. Benton AL, Varney N, Hamsher K. Visuospatial judgment: a clinical test. Arch Neurol. 1978;35:364-7.

55. Sheridan LK, Fitzgerald HE, Adams KM, et al. Normative Symbol Digit Modalities Test performance in a community-based sample. Arch Clin Neuropsychol. 2006;21:23-8.
56. Ye FQ, Berman KF, Ellmore $\mathrm{T}$, et al. $\mathrm{H}_{2}{ }^{15} \mathrm{O}$ PET validation of steady-state arterial spin tagging cerebral blood flow measurements in humans. Magn Reson Med. 2000;44:450-6.

57. Prickett TCR, Olney RC, Cameron VA, Ellis MJ, Richards AM, Espiner EA Impact of age, phenotype and cardio-renal function on plasma C-type and B-type natriuretic peptide forms in healthy adults. Clin Endocrinol. 2013;78:783-9.

58. McCullagh P, Nelder J. Generalized Linear Models. 2nd ed. Boca Raton: Chapman and Hall/CRC; 1989.

59. Dupont WD, Plummer WD. Power and sample size calculations: A review and computer program. Control Clin Trials. 1990;11:116-28.

60. Diggle PJ, Heagerty P, Liang K-Y, Zeger SL (2002). Analysis of Longitudinal Data. Oxford Statistical Science Series. ISBN 9780198524847

61. Roberts D, Dalziel SR. Antenatal corticosteroids for accelerating fetal lung maturation for women at risk of preterm birth. Cochrane Database of Systematic Reviews 2006, Issue 3. Art. No.: CD004454. DOI: 10.1002/ 14651858.CD004454.pub2.

62. Doyle LW, Faber B, Callanan C, et al. Bronchopulmonary dysplasia in very low birth weight subjects and lung function in late adolescence. Pediatrics. 2006;118:108-13.

63. Kajantie E1, Strang-Karlsson S, Hovi P, Wehkalampi K, Lahti J, Kaseva N, et al. Insulin sensitivity and secretory response in adults born preterm: the Helsinkie Study of Very Low Birth Weight Adults. J Clin Endocrinol Metab. 2015;100:244-50

64. Lindström K, Winbladh B, Haglund B, Hjern A. Preterm infants as young adults: a Swedish national cohort study. Pediatrics. 2007;120:70-7.

65. Ekeus $\mathrm{C}$, Lindström $\mathrm{K}$, Lindblad $\mathrm{F}$, et al. Preterm birth, social disadvantage, and cognitive competence in Swedish 18 to 19-year-old men. Pediatrics. 2010;125:e67-73.

66. Moster D, Lie RT, Markestad T. Long-term medical and social consequences of preterm birth. N Engl J Med. 2008;359:262-73.

67. Mathiasen R, Hansen BOM, Nybo Anderson A-M. Socio-economic achievements of individuals born very preterm at the age of 27 to 29 years: a nationwide cohort study. Devel Med Child Neurol. 2009;51:901-8.

68. Walther FJ, den Ouden AL, Verloove-Vanhorick SP. Looking back in time: outcome of a national cohort of very preterm infants born in the Netherlands in 1983. Early Hum Devel. 2000;59:175-91.

69. Hille ET, Weisglas-Kuperus N, van Goudoever JB, et al. Functional outcomes and participation in young adulthood for very preterm and very low birth weight infants: the Dutch Project on Preterm and Small for Gestational Age Infants at 19 years of age. Pediatrics. 2007;120:e587-95.

70. Kajantie E, Hovi P. Is very preterm birth a risk factor for adult cardiometabolic disease? Semin Fetal Neonatal Med. 2014;19:112-7.

\section{Submit your next manuscript to BioMed Central and take full advantage of:}

- Convenient online submission

- Thorough peer review

- No space constraints or color figure charges

- Immediate publication on acceptance

- Inclusion in PubMed, CAS, Scopus and Google Scholar

- Research which is freely available for redistribution 